\title{
Association between Severity of Anemia and 30-Day Readmission Rate: Archival Data of 847 Patients with Acute Decompensated Heart Failure
}

\author{
Jorge C. Busse, ${ }^{1}$ Tanya M. Cohn, ${ }^{2}$ Rosalina Butao, ${ }^{1}$ and Julie Lamoureux ${ }^{1}$ \\ ${ }^{1}$ West Kendall Baptist Hospital, 9555 SW 162nd Avenue, Miami, FL 33196, USA \\ ${ }^{2}$ Baptist Health South Florida, 8500 SW 117th Road, Miami, FL 33183, USA \\ Correspondence should be addressed to Julie Lamoureux; drjuliel@comcast.net
}

Received 10 April 2014; Revised 22 June 2014; Accepted 25 June 2014; Published 14 July 2014

Academic Editor: Francois Madore

Copyright (C) 2014 Jorge C. Busse et al. This is an open access article distributed under the Creative Commons Attribution License, which permits unrestricted use, distribution, and reproduction in any medium, provided the original work is properly cited.

Hospitals today are facing adjustments to reimbursements from excessive readmission rates. One of the most common and expensive causes of readmissions is exacerbation of a heart failure condition. The objective of this paper was to determine if there was an association between the presence of anemia in patients with acute decompensated heart failure and their readmission rate. Using archival data of 4 hospitals in the Miami area, a sample of 847 inpatients with a diagnostic related group (DRG) of HF at discharge was considered. There was a significant association between low hemoglobin values and a high rate of readmissions at 14 days and at 30 days in subjects with normal sodium and creatinine values. For subjects with low sodium and high creatinine values, a higher readmission rate was seen in men with low hemoglobin but not in women. These results support a prospective effort to measure the impact of anemia and its treatment on readmission rates.

\section{Introduction}

Readmission within 30 days of a hospitalization discharge is a popular topic in current healthcare as the Centers for Medicare and Medicaid Services are targeting readmission rates to reduce costs. In 2007, the Medicare Payment Advisory Commission (MedPac) identified seven conditions and procedures that accounted for almost $30 \%$ of potentially preventable readmissions [1]. Nationally, the population with a diagnosis of chronic heart failure (HF) constitutes one of the highest risk populations for readmissions within 30 days of a hospitalization and HF is the most common cause of preventable readmission [2]. Specifically, individuals with HF are most often readmitted with acute decompensated heart failure (ADHF) which is a sudden or gradual onset of heart failure symptoms [3]. The balance between payment penalties and restructuration of policies to reduce readmission rates has been discussed at length and yet there is a lack of discussion about best practices. Are readmissions of patients with heart failure (HF) preventable, and, if so, can simple integrated approaches help reduce this readmission rate? Mazimba et al. [4] found that, with the exception of the left ventricular ejection fraction, the traditional performance measures in HF (like smoking cessation, the use of ACE inhibitors, the measure of the left ventricular ejection fraction, and discharge instructions) were poorly associated with the readmission rate in the HF population.

Anemia is a common comorbidity in patients with HF, being diagnosed in roughly $30 \%$ of nonhospitalized and nearly $50 \%$ of hospitalized HF patients [5]. During a 3.5-year follow-up of over 2000 patients with HF, 29\% of the patients developed anemia [6]. Anemia is common in individuals with HF due to a combination of factors: chronic kidney failure resulting in reduced Erythropoietin (EPO) production; elevated cytokines that cause hematological abnormalities; use of angiotensin converting enzymes (ACE) inhibitors and angiotensin receptor blockers which reduce EPO activity; the coexistence of HF with diabetes; hemodilution; and gastrointestinal problems [5]. Furthermore, renal function has been found to be a strong predictor of anemia for $\mathrm{HF}$ patients [7].

It has been reported in the literature that anemia, particularly severe anemia, was a factor associated with more 
morbidity and mortality in the HF population [5, 7-11]. O'Meara et al. [7] found that anemia was an independent predictor of adverse hospitalization, mortality, and morbidity outcomes for patients with HF. Yet, the MAGGIC metaanalysis of six clinical trials and 30 cohort studies did not identify anemia as a predictive variable for mortality in patients with HF [12]. This varying view supports Go et al.s [13] indication of the need for more clinical trials to support their findings that HF patients are at a higher risk of death and hospitalization if they have very high or very low hemoglobin levels. Kosiborod et al. [10] and O'Meara et al. [7] both concluded that anemia is associated with an increased risk of death and rehospitalization in older patients with HF. Groenveld et al. [8] and Von Haehling et al. [11] also indicate that anemia is associated with a higher risk of mortality in HF patients. When left untreated, anemia in the follow-up period will continue to worsen resulting in increased potential for readmission and mortality of the patient [5].

Anemia is diagnosed using a simple routine blood test. The diagnosis of anemia is usually based on the hemoglobin $(\mathrm{Hb})$ level of a patient. In 1968, the World Health Organization (WHO) expert committee suggested cut-offs for the diagnosis of anemia for male patient at $\mathrm{Hb}<13.0 \mathrm{~g} / \mathrm{dL}$ and at $\mathrm{Hb}<12.0 \mathrm{~g} / \mathrm{dL}$ for female patients [14]. On the other hand, it is not uncommon for researchers to use different cut-points for $\mathrm{Hb}$ or use $\mathrm{Ht}$ as a diagnostic tool for anemia.

In an effort to truly become a learning organization, looking at our own population and our site-specific data, we used impressions of various clinicians as a starting point to explore HF readmissions and prevalence of anemia. This lead suggested that anemia was present in a significant portion of readmitted patients with a diagnosis of HF. Thus, this study aimed at determining if there existed an association between the presence of anemia left untreated and the readmission rate for the HF patients and, more specifically, identifying subgroups of this population that would potentially benefit more from the treatment of the anemia.

\section{Methods}

This study was a secondary analysis of archival data of all patients with a diagnostic related group (DRG) of HF discharged from four hospitals in the Miami metropolitan area between October 1st 2011 and March 31st 2012. Excluded from this sample were those who expired during their stay, those who left against medical advice, those who were in observation status during their stay, and those who were transferred to another acute care hospital other than the ones selected in this study. The charts of those patients meeting inclusion criteria were reviewed and the following data was extracted: gender, age, ethnicity, severity of the condition, length of stay in the hospital, hemoglobin levels before discharge, hematocrit concentration before discharge, blood levels of Iron before discharge, total Iron binding capacity (TIBC) before discharge, creatinine levels before discharge, sodium levels before discharge, destination at discharge, if the patient was readmitted for any reason in any of the hospital in the system, and, if so, the number of days until readmission. The severity of the $\mathrm{ADCH}$ was defined as a coding variable.

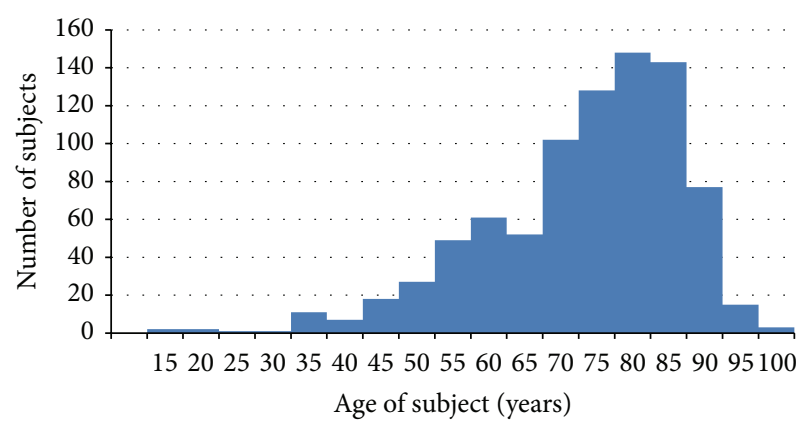

FIGURE 1: Distribution of ages in sample $(n=847)$.

There are three DRGs that result from the documentation of the condition during the hospitalization: DRG 291 represents the most severe case and is attributed to patients with heart failure with major comorbidities and complications; DRG 292 represents a moderate case and is attributed to patients with heart failure with comorbidities and complications but none of them major; finally DRG 293 represents the least severe case and is attributed to patients with heart failure without comorbidities or complications. IRB approval was received for this study.

\section{Results}

Descriptive statistics were done using proportions for categorical variables and means, standard deviations, and ranges for the numerical variables. To compare the rates of readmissions between the groups, chi-square statistics were done. In order to determine if the readmission rate was determined partly by the anemia when considering other factors, a predictive logistic regression model was built for readmissions at 14 days and readmissions at 30 days after discharge. Some interactions were considered in the predictive model when theoretically warranted. The level of significance was set at 0.05 for all analyses. All analyses were done using STATA 12.1 (StataCorp, Texas).

The total sample collected showed 1201 patients discharged between October 1, 2011, and March 31, 2012, with a DRG of 291, 292, or 293. Of those, 847 satisfied the inclusion criteria previously stated. Overall, $12.4 \%(n=105)$ patients were readmitted within 14 days after discharge, and $21.8 \%$ $(n=185)$ were readmitted within 30 days after discharge. About 29\% of the cases were severe cases (DRG 291), 51\% were of intermediate severity (DRG 292), and 21\% were the least severe cases (DRG 293). This severity case mix was not significantly different between the readmitted and not readmitted groups at 14 days $\left(\chi_{2 \mathrm{df}}^{2}=0.481, P=0.786\right)$ or at 30 days $\left(\chi_{2 \mathrm{df}}^{2}=4.417, P=0.110\right.$ ). Table 1 shows the descriptive statistics for the sample as well for the readmitted and not readmitted groups.

Overall, the age of the sample ranged from 20 to 102 years with an average $( \pm S D)$ of $76.3 \pm 13.7$. Figure 1 shows the distribution of ages in the sample. The overall percentage of males was $47.2 \%$. The average length of stay (LOS) was $4.5 \pm 4.1$ with a range of 1 to 42 days. The average creatinine value was $1.66 \pm 1.44$ with a range from 0.31 to $19.76 \mathrm{mg} / \mathrm{dL}$. 
TABLE 1: Descriptive statistics of study population overall, by readmitted and not readmitted groups.

\begin{tabular}{|c|c|c|c|c|c|}
\hline Variable & Overall & $\begin{array}{l}\text { Readmitted } \\
14 \text { days }\end{array}$ & $\begin{array}{l}\text { Not readmitted } \\
14 \text { days }\end{array}$ & Test & Significance \\
\hline Age (years) & $76.3 \pm 13.7$ & $74.4 \pm 14.1$ & $76.6 \pm 13.6$ & $t_{845 \mathrm{df}}=1.550$ & 0.122 \\
\hline Ethnicity (\% Hispanic) & $59.9 \%$ & $54.8 \%$ & $60.6 \%$ & $\chi_{1 \mathrm{df}}^{2}=1.284$ & 0.257 \\
\hline$\%$ males & $47.2 \%$ & $47.6 \%$ & $47.2 \%$ & $\chi_{1 \mathrm{df}}^{2}=0.007$ & 0.931 \\
\hline \multicolumn{6}{|l|}{ DRG } \\
\hline 291 & $28.6 \%$ & $29.5 \%$ & $28.4 \%$ & \multirow{3}{*}{$\chi_{2 \mathrm{df}}^{2}=0.481$} & \multirow{3}{*}{0.796} \\
\hline 292 & $50.8 \%$ & $52.4 \%$ & $50.5 \%$ & & \\
\hline 293 & $20.7 \%$ & $18.1 \%$ & $21.0 \%$ & & \\
\hline Length of stay (days) & $4.5 \pm 4.1$ & $4.9 \pm 4.2$ & $4.5 \pm 4.1$ & $t_{845 \mathrm{df}}=1.037$ & 0.300 \\
\hline Creatinine values $(\mathrm{mg} / \mathrm{dL})$ & $1.66 \pm 1.45$ & $1.87 \pm 1.69$ & $1.63 \pm 1.41$ & $t_{125.4 \mathrm{df}}=1.399^{*}$ & 0.164 \\
\hline Sodium values $(\mathrm{mEq} / \mathrm{L})$ & $138.02 \pm 4.09$ & $136.88 \pm 4.26$ & $138.18 \pm 4.04$ & $t_{835 \mathrm{df}}=3.080$ & 0.002 \\
\hline Hemoglobin values (g/dL) & $11.47 \pm 1.80$ & $11.23 \pm 1.72$ & $11.50 \pm 1.81$ & $t_{834 \mathrm{df}}=1.474$ & 0.141 \\
\hline Hematocrit values (\%) & $35.34 \pm 5.25$ & $34.57 \pm 5.00$ & $35.45 \pm 5.28$ & $t_{834 \mathrm{df}}=1.599$ & 0.110 \\
\hline Iron values ${ }^{* *}(\mu \mathrm{g} / \mathrm{dL})$ & $45.87 \pm 31.16$ & $49.88 \pm 30.70$ & $45.25 \pm 31.28$ & $t_{184 \mathrm{df}}=0.690$ & 0.491 \\
\hline TIBC values $^{* *}(\mu \mathrm{g} / \mathrm{dL})$ & $283.14 \pm 90.84$ & $240.08 \pm 97.76$ & $289.87 \pm 88.15$ & $t_{183 \mathrm{df}}=2.588$ & 0.010 \\
\hline Variable & Overall & $\begin{array}{l}\text { Readmitted } \\
30 \text { days }\end{array}$ & $\begin{array}{c}\text { Not readmitted } \\
30 \text { days } \\
\end{array}$ & Test & Significance \\
\hline Age (years) & $76.3 \pm 13.7$ & $74.8 \pm 14.0$ & $76.7 \pm 13.6$ & $t_{845 \mathrm{df}}=1.687$ & 0.092 \\
\hline Ethnicity (\% Hispanic) & $59.9 \%$ & $56.3 \%$ & $60.9 \%$ & $\chi_{1 \mathrm{df}}^{2}=1.278$ & 0.258 \\
\hline$\%$ males & $47.2 \%$ & $46.5 \%$ & $47.4 \%$ & $\chi_{1 \mathrm{df}}^{2}=0.052$ & 0.820 \\
\hline \multicolumn{6}{|l|}{ DRG } \\
\hline 291 & $28.6 \%$ & $30.8 \%$ & $28.0 \%$ & \multirow{3}{*}{$\chi_{2 \mathrm{df}}^{2}=4.417$} & \multirow{3}{*}{0.110} \\
\hline 292 & $50.8 \%$ & $54.1 \%$ & $49.9 \%$ & & \\
\hline 293 & $20.7 \%$ & $15.1 \%$ & $22.1 \%$ & & \\
\hline Length of stay (days) & $4.5 \pm 4.1$ & $4.8 \pm 3.8$ & $4.4 \pm 4.2$ & $t_{845 \mathrm{df}}=0.956$ & 0.339 \\
\hline Creatinine values (mg/dL) & $1.66 \pm 1.45$ & $1.69 \pm 1.45$ & $1.65 \pm 1.45$ & $t_{835 \mathrm{df}}=0.361$ & 0.718 \\
\hline Sodium values (mEq/L) & $138.02 \pm 4.09$ & $137.19 \pm 4.23$ & $138.25 \pm 4.02$ & $t_{835 \mathrm{df}}=3.147$ & 0.002 \\
\hline Hemoglobin values (g/dL) & $11.47 \pm 1.80$ & $11.31 \pm 1.78$ & $11.51 \pm 1.81$ & $t_{834 \mathrm{df}}=1.368$ & 0.172 \\
\hline Hematocrit values (\%) & $35.34 \pm 5.25$ & $34.83 \pm 5.18$ & $35.49 \pm 5.27$ & $t_{834 \mathrm{df}}=1.488$ & 0.137 \\
\hline Iron values ${ }^{* *}(\mu \mathrm{g} / \mathrm{dL})$ & $45.87 \pm 31.16$ & $45.30 \pm 25.90$ & $46.03 \pm 32.54$ & $t_{184 \mathrm{df}}=0.130$ & 0.896 \\
\hline TIBC values $^{* *}(\mu \mathrm{g} / \mathrm{dL})$ & $283.14 \pm 90.84$ & $274.52 \pm 121.24$ & $285.52 \pm 80.85$ & $t_{49.0 \mathrm{df}}=0.541^{*}$ & 0.591 \\
\hline
\end{tabular}

* Satterthwaite correction for unequal variances.

${ }^{* *}$ There were 186 iron values and 185 TIBC values.

Almost forty percent (37.3\%) of the sample had high creatinine as defined by a value above $1.5 \mathrm{mg} / \mathrm{dL}$. The average hemoglobin value was $11.47 \pm 1.80$ with a range between 7.1 and $17.1 \mathrm{~g} / \mathrm{dL}$. More than twenty percent $(23.1 \%)$ of the sample had a value of less than $10 \mathrm{~g} / \mathrm{dL}$ for their hemoglobin. The average hematocrit concentration was $35.35 \% \pm 5.25 \%$ with a range between $22.9 \%$ and $53.6 \%$. None of those variables differed significantly between the readmitted and the nonreadmitted subjects. The average sodium value was significantly lower in the readmitted group compared to the nonreadmitted group. Overall, the average value for sodium was $138.01 \pm 4.09$ with a range between 120 and $150 \mathrm{mEq} / \mathrm{L}$. Overall, more than twenty percent $(23.7 \%)$ of the subjects were hyponatremic, as defined by a sodium value of less than $130 \mathrm{mEq} / \mathrm{L}$. The iron and the TIBC values are given in Table 1 but there were very few available values $(n=186$ for iron and $n=185$ for TIBC). Since we do not know the reasons for this high proportion of missing values, these variables will not be used in the predictive analyses.

Of the 847 inpatients, 423 (50.0\%) were discharged home, $274(32.3 \%)$ were discharged to home health services, and 62 (7.3\%) were discharged to a skilled nursing facility (SNF). The rest $(10 \%)$ were discharged to other locations. This discharge pattern was significantly different between those who were readmitted within 14 days and those who were not $\left(\chi_{8 \mathrm{df}}^{2}=\right.$ $16.105, P=0.041)$. Of those who were readmitted within 14 days, a higher percentage was discharged to a skilled nursing facility $(14.3 \%)$ compared to those who were not readmitted (6.3\%). This discharge pattern was also significantly different between those who were readmitted within 30 days and those who were not $\left(\chi_{8 \mathrm{df}}^{2}=30.587, P<0.001\right)$. Of those who were readmitted within 30 days, a higher percentage was discharged to a skilled nursing facility (13.0\%) compared to those who were not readmitted (5.71\%). Also, of those 
TABLE 2: Percentage of patients with abnormal blood tests in the readmitted and not readmitted groups.

\begin{tabular}{|c|c|c|c|c|}
\hline & $\begin{array}{l}\text { Readmitted } \\
14 \text { days }\end{array}$ & $\begin{array}{l}\text { Not readmitted } \\
14 \text { days }\end{array}$ & Test & Sig. \\
\hline Hyponatremia & $36.2 \%$ & $21.9 \%$ & $\chi_{1 \mathrm{df}}^{2}=10.445$ & 0.001 \\
\hline High creatinine & $40.0 \%$ & $37.0 \%$ & $\chi_{1 \mathrm{df}}^{2}=0.348$ & 0.555 \\
\hline \multirow[t]{2}{*}{ Hemoglobin $<10 \mathrm{~g} / \mathrm{dL}$} & $28.6 \%$ & $22.4 \%$ & $\chi_{1 \mathrm{df}}^{2}=1.940$ & 0.164 \\
\hline & $\begin{array}{l}\text { Readmitted } \\
30 \text { days }\end{array}$ & $\begin{array}{c}\text { Not readmitted } \\
30 \text { days }\end{array}$ & Test & Sig. \\
\hline Hyponatremia & $31.3 \%$ & $21.5 \%$ & $\chi_{1 \mathrm{df}}^{2}=7.788$ & 0.005 \\
\hline High creatinine & $37.3 \%$ & $37.4 \%$ & $\chi_{1 \mathrm{df}}^{2}=0.001$ & 0.975 \\
\hline Hemoglobin $<10 \mathrm{~g} / \mathrm{dL}$ & $27.6 \%$ & $22.0 \%$ & $\chi_{1 \mathrm{df}}^{2}=2.536$ & 0.111 \\
\hline
\end{tabular}

who were readmitted within 30 days, a higher percentage was discharged to home health services (35.1\%) compared to those who were not readmitted $(31.6 \%)$.

In this study, the blood components values were recoded to simplify the investigation of interactions in the predictive model. Hyponatremia (defined as sodium of less than $130 \mathrm{mEq} / \mathrm{L}$ ) was significantly associated with the risk of being readmitted within 14 days $\left(\chi_{1 \mathrm{df}}^{2}=10.445, P=0.001\right) ; 36 \%$ of those who were readmitted were hyponatremic compared to $22 \%$ of those who were not readmitted (see Table 2). High creatinine (defined as creatinine of more than $1.5 \mathrm{mg} / \mathrm{dL}$ ) was not significantly associated with the risk of readmission within 14 days $\left(\chi_{1 \mathrm{df}}^{2}=0.348, P=0.555\right)$. Overall, having a hemoglobin of less than $10 \mathrm{~g} / \mathrm{dL}$ was not significantly associated with the risk of being readmitted within 14 days $\left(\chi_{1 \mathrm{df}}^{2}=1.940, P=0.164\right)$.

Hyponatremia was significantly associated with the risk of being readmitted within 30 days $\left(\chi_{1 \mathrm{df}}^{2}=7.788, P=\right.$ $0.005) ; 31 \%$ of those who were readmitted were hyponatremic compared to $22 \%$ of those who were not readmitted. High creatinine was not significantly associated with the risk of readmission within 30 days $\left(\chi_{1 \mathrm{df}}^{2}=0.001, P=0.975\right)$. Overall, having hemoglobin of less than $10 \mathrm{~g} / \mathrm{dL}$ was not significantly associated with the risk of being readmitted within 30 days $\left(\chi_{1 \mathrm{df}}^{2}=2.536, P=0.111\right)$.

Using logistic regression models to predict readmissions at 14 and 30 days (using DRG, gender, age, ethnicity, hyponatremia status, high creatinine status, and hemoglobin values for predictors), it was found that there were significant 2-way interactions between the gender and sodium and creatinine levels. We therefore ran subanalyses to determine which ones of the subgroups' readmissions were dependent on anemia.

For the subjects with normal sodium and normal creatinine $(n=402)$, having a hemoglobin value superior to $10 \mathrm{~g} / \mathrm{dL}$ was significantly associated with a lower rate of readmission at 14 days $(95 \%$ CI for the odds ratio $=[0.645 ; 0.959])$. In fact, $15.9 \%$ of the subjects with a hemoglobin value of less than $10 \mathrm{~g} / \mathrm{dL}$ in this group were readmitted at 14 days, compared to $8.6 \%$ in the group with hemoglobin of more than $10 \mathrm{~g} / \mathrm{dL}$. The effect of having low hemoglobin was not associated with the rate of readmissions at 30 days in this group (95\% CI for the odds ratio $=[0.185 ; 5.150])$.

For the subjects with low sodium and high creatinine $(n=$ 79), there was a significant interaction between hemoglobin levels and gender $(P=0.05)$. When breaking down by gender, ( $n=34$ for females and $n=46$ for males), the association was significant only for males, with an average odds ratio of 12 times more at risk of readmission at 14 days for those with a hemoglobin value of less than $10 \mathrm{~g} / \mathrm{dL}$ compared to those with hemoglobin of $10 \mathrm{~g} / \mathrm{dL}$ or more (95\% CI for the odds ratio $=[1.891 ; 71.977])$. In fact, $50.0 \%$ of male subjects with hemoglobin of less than $10 \mathrm{~g} / \mathrm{dL}$ in this group were readmitted at 14 days, compared to $7.9 \%$ in the group with hemoglobin of more than $10 \mathrm{~g} / \mathrm{dL}$. For women with low sodium and high creatinine, there was no significant association between hemoglobin levels and readmissions at 14 days. The level of hemoglobin was not significantly associated with the rate of readmission at 30 days $(95 \% \mathrm{CI}$ for the odds ratio $=[0.813$; 9.185]) for this subgroup.

For the subjects who had only one abnormal measure in sodium and creatinine (either low sodium or high creatinine, $n=350$ ), we could not identify an association between the level of hemoglobin and the rate of readmission at 14 or 30 days.

\section{Discussion}

Although the association between anemia and outcome of $\mathrm{ADHF}$ patients has been described in recent years, the marginal effect of anemia on readmissions has not been explored when controlling for factors like sodium levels and creatinine levels. This paper aimed at isolating a relation between anemia in HF patients that were hospitalized and their readmission rate. It is well established that hyponatremia is a marker of more severe cardiac dysfunction in patients with ADHF and that abnormal renal function affords an increased risk of cardiovascular disease as evident by Androne et al. [15]. In theory, anemia should increase the burden on the failing heart which struggles to maintain adequate delivery of oxygen. The combination of hyponatremia, anemia, and abnormal renal function seems to promote a synergistically detrimental effect on the failing heart resulting in an increased rate of readmission, especially in men. This study's synergistically detrimental effect supports O'Meara et al.s [7] work in the CHARM study regarding the predicative relationship of renal impairment for anemia in patients with HF. Furthermore, the increased risk of readmissions in men that was found in this study suggests 
the need to further evaluate sex. This is especially true as the MAGGIC meta-analysis [12] found that males are a predictive risk factor of mortality for patients with HF; however, the CHARM study found that females were more likely to be associated with anemia [12]. Thus, further prospective work is needed to more clearly identify the role of sex in risks and outcomes for patients with HF.

Bivariately, hemoglobin and hematocrit values were not significantly associated with the rate of readmission but, when controlling for factors like sodium and creatinine levels, it was found that anemia was a contributing factor in explaining the relative frequency of readmissions. This is particularly interesting as Androne et al. [15] found that hemodilution, often found in patients with low sodium, resulted in poorer outcomes versus true anemia. Among the subjects with normal creatinine and normal sodium, those with hemoglobin of $10 \mathrm{~g} / \mathrm{dL}$ or more had proportionally less readmissions than those with hemoglobin below $10 \mathrm{~g} / \mathrm{dL}$. Furthermore, among males with low sodium and high creatinine, it was found that those with hemoglobin of $10 \mathrm{~g} / \mathrm{dL}$ or more had proportionally less readmissions than those with hemoglobin below 10 . These findings, without demonstrating causality, suggest a compounding effect of severe anemia on the readmission rate of $\mathrm{HF}$ patients.

There are limitations to this study. The selection of the sample was based on Disease Related Groups (DRG) of hospitalized ADHF patients. It therefore excludes all patients who were under observation for HF exacerbation, a group of HF patients that are usually less sick but have the same condition. Also, the readmission rate was defined as "all-cause" readmissions, following the definition used by CMS. Although we can postulate that the bias in "all-cause" readmission is the same for all patients, this bias cannot be measured and therefore cannot be assumed to be constant. In addition, previous research, such as the MAGGIC metaanalysis [12], has found specific predictors of mortality for patients with HF which were not included in this study. For example, although the ejection fraction is measured for all patients in ADHF, this data was not accessible in this electronic data source. Also, even if nonadherence to medication was believed to be a causal factor in readmission, it was not possible to control this variable in our sample. Therefore, further work to assess such predictors and their potential association with readmission at the 14- and 30day points should prove to be beneficial. Finally, finding an association between anemia level and readmission rates in retrospective data collection does not imply that treating the anemia would positively and significantly impact the readmission rate.

However, our study did demonstrate some association between sodium, creatinine, anemia, and readmissions. This is particularly important as, compared to the majority of research on this subject matter resulting from clinical trials, this study drew data from the real life clinical setting thus providing a perspective of clinical outcomes within a hospital. This argues the need to prospectively, in the clinical setting, assess these values in the clinical setting along with implementing treatment protocols that address them. We hypothesize that a large number of hospitalized anemic patients are iron deficient $(70 \%$ of the patients whose Transferrin saturation was measured having their value below $20 \%$ and $85 \%$ below $30 \%$ ); it would be fairly simple to iron replete these patients in a short time with newer parenteral iron formulations. Unfortunately, we have no information as to the source of the anemia and can only hypothesize about the role of iron in making this population better. Therefore, based on our results and limitations to our study, we strongly support prospective efforts to measure the impact of anemia and its treatment on readmission rates.

\section{Conflict of Interests}

The authors declare that they have no conflict of interests regarding the publication of this paper.

\section{References}

[1] G. M. Hackbarth, R. D. Reischauer, and M. E. Miller, Report to the Congress: Reforming the Delivery System, Medicare Payment Advisory Commission, Washington, DC, USA, 2008.

[2] S. F. Jencks, M. V. Williams, and E. A. Coleman, "Rehospitalizations among patients in the medicare fee-for-service program," The New England Journal of Medicine, vol. 360, no. 14, pp. 14181428, 2009.

[3] S. M. Joseph, A. M. Cedars, G. A. Ewald, E. M. Geltman, and D. L. Mann, "Acute decompensated heart failure," Texas Heart Institute Journal, vol. 36, no. 6, pp. 510-520, 2009.

[4] S. Mazimba, N. Grant, A. Parikh et al., "Heart failure Performance measures: do they have an impact on 30-day readmission rates?" American Journal of Medical Quality, vol. 28, no. 4, pp. 324-329, 2013.

[5] D. S. Silverberg, D. Wexler, A. Iaina, and D. Schwartz, "The role of correction of anaemia in patients with congestive heart failure: a short review," European Journal of Heart Failure, vol. 10, no. 9, pp. 819-823, 2008.

[6] W. H. W. Tang, W. Tong, A. Jain, G. S. Francis, C. M. Harris, and J. B. Young, "Evaluation and long-term prognosis of newonsel, transient, and persistent anemia in ambulatory patients with chronic heart failure," Journal of the American College of Cardiology, vol. 51, no. 5, pp. 569-576, 2008.

[7] E. O'Meara, T. Clayton, M. B. McEntegart et al., "Clinical correlates and consequences of anemia in a broad spectrum of patients with heart failure-results of the candesartan in heart failure: assessment of reduction in mortality and morbidity (CHARM) program," Circulation, vol. 113, no. 7, pp. 986-994, 2006.

[8] H. F. Groenveld, J. L. Januzzi, K. Damman et al., "Anemia and mortality in heart failure patients: a systematic review and metaanalysis," Journal of the American College of Cardiology, vol. 52, no. 10 , pp. $818-827,2008$.

[9] E. A. Jankowska, P. Rozentryt, A. Witkowska et al., "Iron deficiency: an ominous sign in patients with systolic chronic heart failure," European Heart Journal, vol. 31, pp. 1872-1880, 2010.

[10] M. Kosiborod, G. L. Smith, M. J. Radford, J. M. Foody, and H. M. Krumholz, "The prognostic importance of anemia in patients with heart failure," The American Journal of Medicine, vol. 114, no. 2, pp. 112-119, 2003. 
[11] S. Von Haehling, J. C. Schefold, L. Majc Hodoscek et al., "Anaemia is an independent predictor of death in patients hospitalized for acute heart failure," Clinical Research in Cardiology, vol. 99, no. 2, pp. 107-113, 2010.

[12] S. J. Pocock, C. A. Ariti, J. J. V. McMurray et al., "Predicting survival in heart failure: a risk score based on 39,372 patients from 30 studies," European Heart Journal, vol. 34, no. 19, pp. 1404-1413, 2013.

[13] A. S. Go, J. Yang, L. M. Ackerson et al., "Hemoglobin level, chronic kidney disease, and the risks of death and hospitalization in adults with chronic heart failure - the anemia in chronic heart failure: outcomes and Resource Utilization (ANCHOR) Study," Circulation, vol. 113, no. 23, pp. 2713-2723, 2006.

[14] B. Blanc, C. A. Finch, L. Hallberg et al., Nutritional Anaemias. Report of a WHO Scientific Group no. 5, Technical Report Series, WHO, Geneva, Switzerland, 1968.

[15] A. S. Androne, S. D. Katz, L. Lund et al., "Hemodilution is common in patients with advanced heart failure," Circulation, vol. 107, no. 2, pp. 226-229, 2003. 


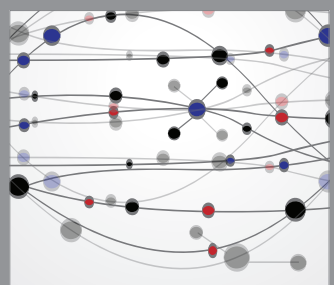

The Scientific World Journal
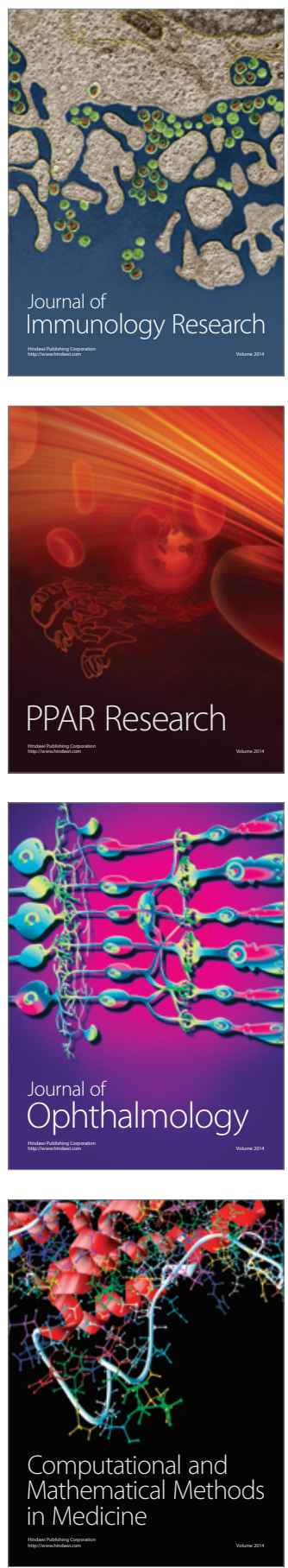

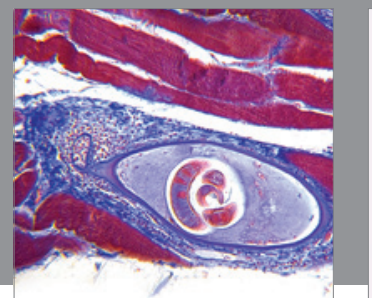

Gastroenterology

Research and Practice
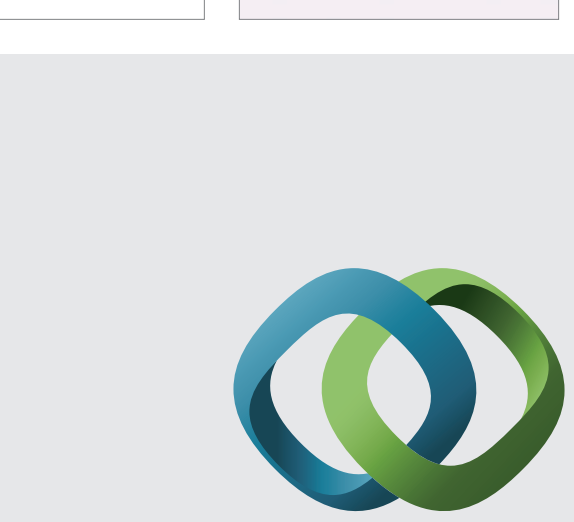

\section{Hindawi}

Submit your manuscripts at

http://www.hindawi.com
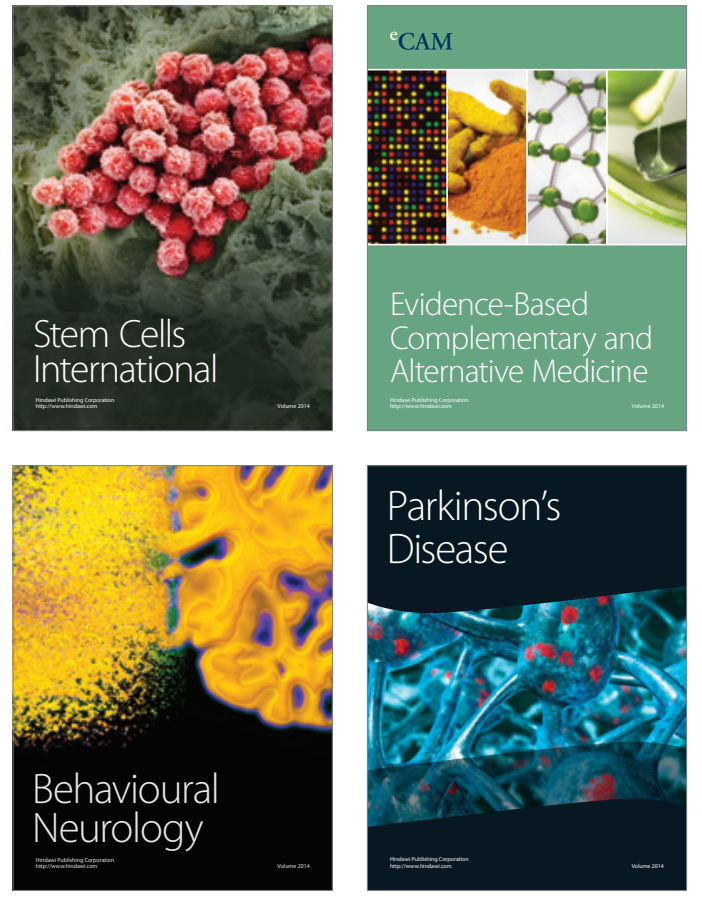
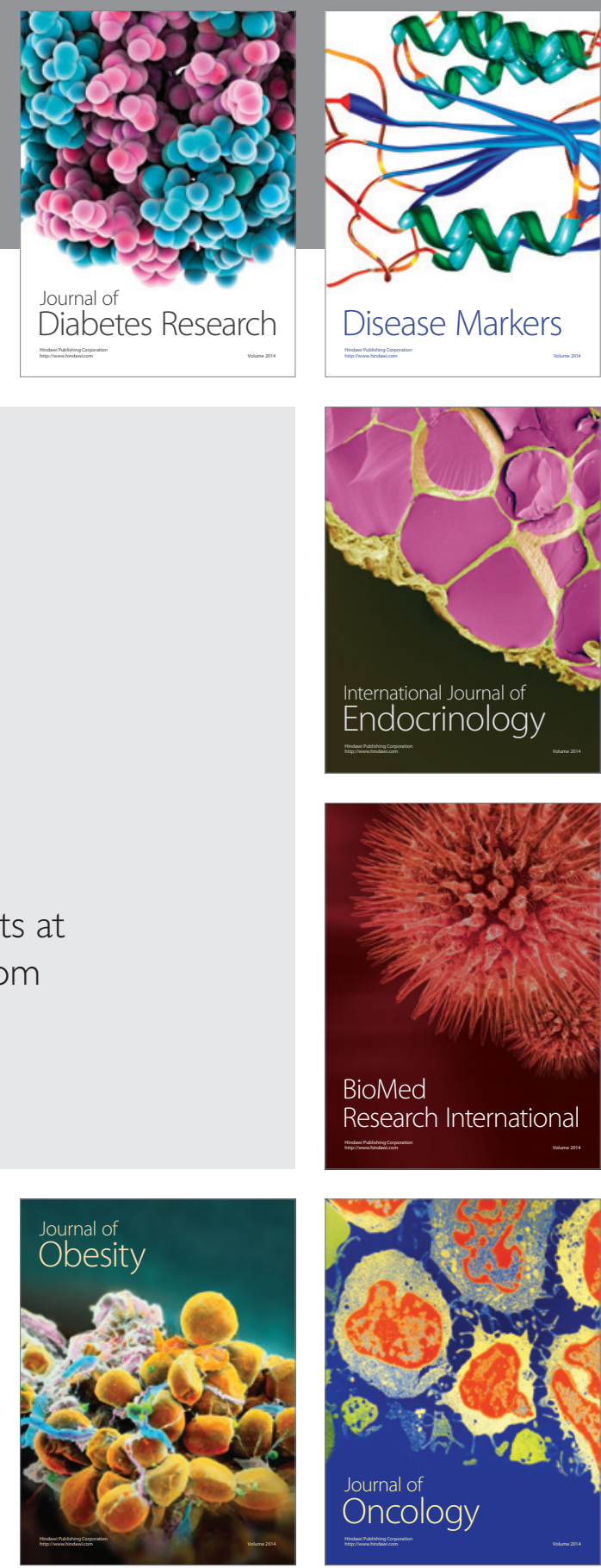

Disease Markers
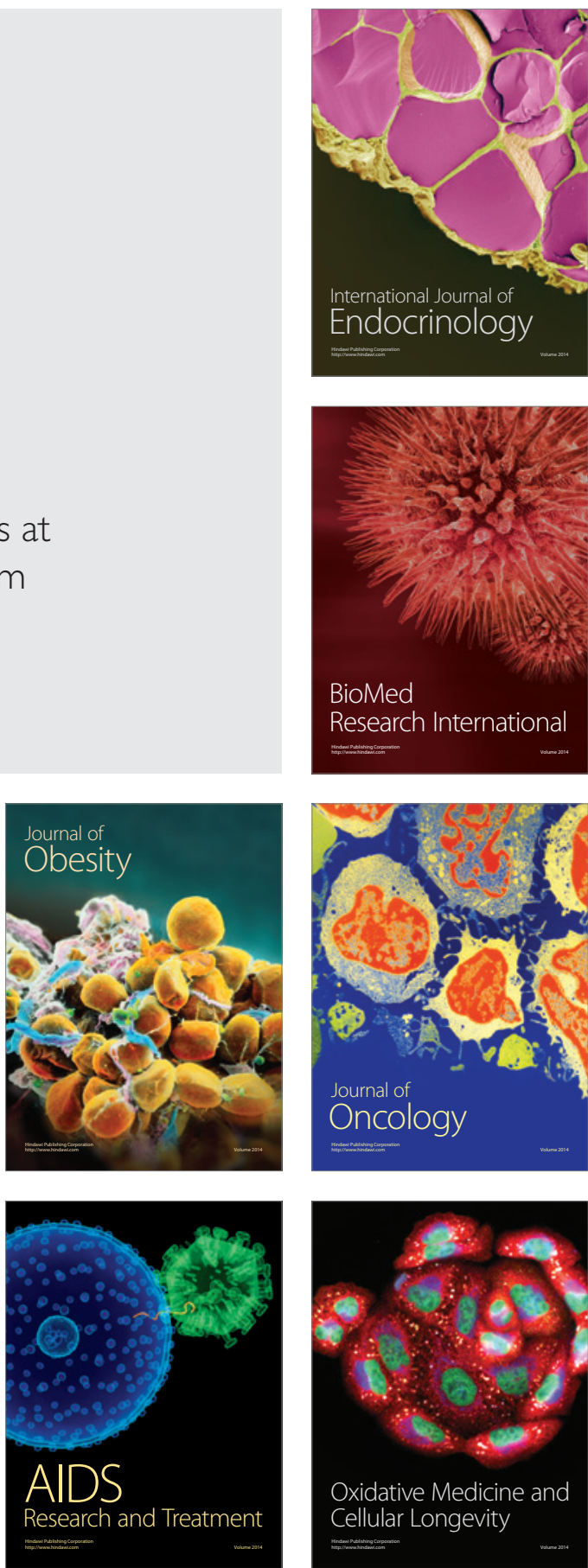